\title{
Oxygen/nitrogen-assisted embrittlement of titanium alloys exposed at elevated temperature
}

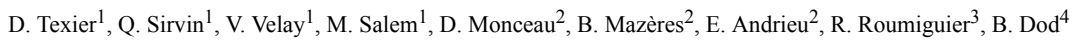 \\ ${ }^{1}$ Institut Clément Ader (ICA) - UMR CNRS 5312 ; Université de Toulouse ; CNRS, IMT Mines Albi, INSA, ISAE-SUPAERO, UPS ; Albi, France \\ ${ }^{2}$ CIRIMAT, Université de Toulouse, CNRS, INP-ENSIACET, 4 allée Emile Monso, BP 44362, 31030, Toulouse Cedex 4, France \\ ${ }^{3}$ MIDIVAL ; Sainte-Foy d'Aigrefeuille, France \\ ${ }^{4}$ AIRBUS ; Toulouse, France
}

\section{Keywords:}

Titanium alloy; Micromechanical tensile testing; Oxidation; Oxygen diffusion; Oxygen embrittlement

\begin{abstract}
:
Due to high solubility of oxygen and nitrogen in titanium alloys, the influence of the diffusion zone on the macroscopic tensile properties of pre-oxidized annealed Ti-6Al-4V tensile specimens was examined at room temperature. Thin microtensile specimens were prepared with different thicknesses ranging from $100 \mu \mathrm{m}$ to $500 \mu \mathrm{m}$ and then exposed at $750^{\circ} \mathrm{C}$ for durations between 5 and $200 \mathrm{~h}$. A dedicated gripping technique was developed in the present study to investigate the brittleness of such pre-oxidized and ultrathin specimens at room temperature. Tensile testing was paired with digital image correlation techniques to assess both macroscopic deformation and full-field strain maps. High temperature pre-oxidation treatments significantly decreased the ductility of the specimen and the tensile strength of the materials (yield strength and ultimate tensile strength). Fractographic examinations revealed typical brittle fracture features in the oxygen/nitrogen-affected diffusion zone in the periphery of the cross-section while the fracture remained ductile in the core of the specimen for

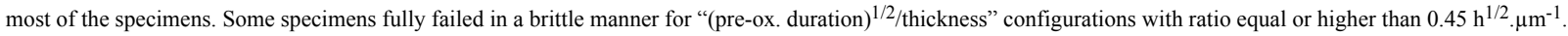

\section{Introduction}

Titanium alloys are increasingly used in the manufacture of intermediate/high temperature structural components. In service, these components are exposed to elevated temperatures $\left(300-600^{\circ} \mathrm{C}\right)$ and oxidative/nitriding atmospheres, typically the air or combustion gases [1]. However, Ti and Ti alloys dissolve large amounts of oxygen and nitrogen (up to $15 \%$ in weight for $\mathrm{O}$ and $7.6 \%$ in weight for $\mathrm{N}$ in the alpha phase) [2]. The high solubility of these interstitial elements leads to their ingress in the metal, by diffusion from the metal/oxide interface during high temperature dwells and thus to the formation of an oxygen/nitrogen-affected diffusion zone (ONADZ) for depths typically one order of magnitude thicker than the oxide layer [3,4]. This gradient of chemical composition could alter the microstructure of Ti alloys but in a greater manner impairs the mechanical properties of the base material by:

1. Increasing the magnitude of the critical resolved shear stress (CRSS) of prismatic, pyramidal and basal planes [5], the yield strength [5-9], the hardening exponent [5,6];

2. Changing deformation modes from single prismatic slip to double prismatic slip or multiple slip [10];

3. Reducing the activation volume and enhancing static and dynamic strain aging phenomena [6,7];

4. Decreasing primary, secondary and tertiary creep rates $[7,11]$;

5. Increasing the hardness $[8,12,13]$;

6 . Increasing the dynamic elastic modulus of oxidized [11];

7. Increasing the lattice parameters and volume unit cell $[6,12]$;

8 . Decreasing the ductility $[6,14,15]$.

Due to the brittleness of the ONADZ and the gradient of concentration in $\mathrm{O}$ and $\mathrm{N}$, this zone strongly impairs the mechanical integrity of Ti-alloys structural components subjected to mechanical loading and thermal exposure, especially for cyclic stresses [13,16,17]. The ONADZ fails in a brittle manner and transverse cracks develop on the whole gauge section, acting as severe notches in service conditions. Therefore, assessing the local mechanical behavior of the ONADZ and predicting its early cracking in various stress amplitude/temperature ranges are central problematics to better implement microstructure-based fatigue criteria in structural design of Ti-alloys components.

In the present study, the tensile behavior of the ONADZ was investigated using microtensile pre-oxidized specimens with different thicknesses and exposure durations at high temperature. Microtensile specimens exhibit a substantial surface/volume ratio that is interestingly appropriate for the study of surface reactivity, i.e. oxidation, nitridation. In other words, playing with the extension of the $\mathrm{O} / \mathrm{N}$ concentration gradient and various thicknesses of remaining unaffected Ti alloy would allow an inverse identification of the local properties within the gradient of $\mathrm{O} / \mathrm{N}$ content, i.e. the gradient of tensile properties.

(a)

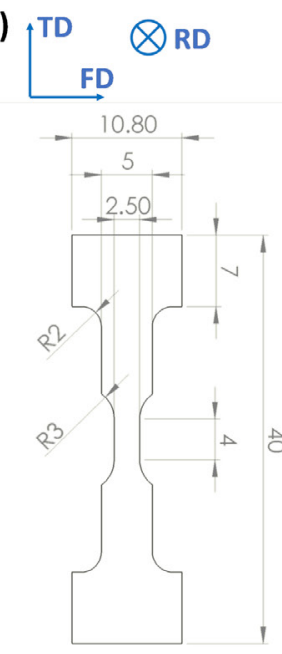

(b)

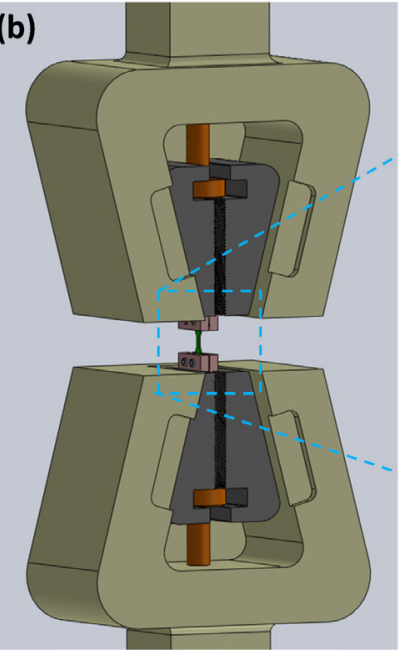

(c)

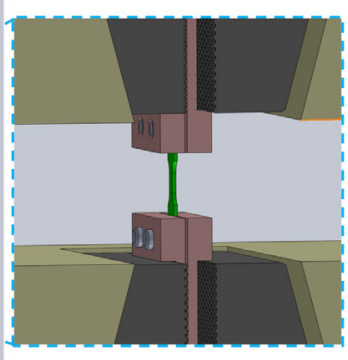

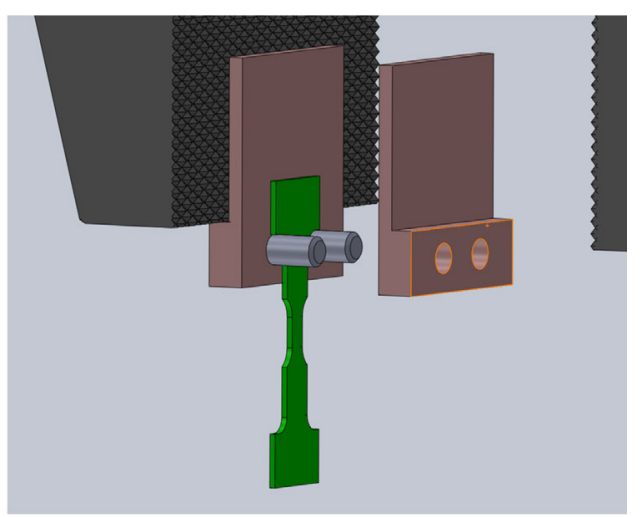

Fig. 1: (a) Specimen geometry (dimensions in $\mathbf{m m}$ ), (b) schematic illustration of the gripping system for brittle micro-tensile specimens, (c) exploded view of the gripping system

\section{Material and experiments}

An annealed Ti-6Al-4V rolled plate was used in the present study with typical acicular Widmanstätten $\alpha-\beta$ microstructure, coarse grains (ASTM of -3.5 ) and a nominal composition as follows: Ti-6Al-4V-0.19Fe-0.12O-0.05C-0.04N (wt. \%). 1-mm-thick microtensile specimens were extracted from the rolled plate via electrodischarge machining with the geometry and the directions in relation to the rolling process defined in Fig. 1(a). Edges were ground down to a P1200 SiC grad paper to remove the EDM-affected region. Microtensile specimens

(C) The Authors, published by EDP Sciences. This is an open access article distributed under the terms of the Creative Commons Attribution License 4.0 (http://creativecommons.org/licenses/by/4.0/). 
were then thinned down to different thicknesses in the range of 100 to $500 \mu \mathrm{m}$ using a LOGITECH CL50 ${ }^{\odot}$ lapping machine equipped with a PP5GT precision Jig and SiC papers down to a P2400 grad paper in order to obtain the required geometrical tolerance for micromechanical testing. This preparation technique is fully detailed in ref. [18]. Four thicknesses were investigated, i.e. $100,180,280$ and $480 \mu \mathrm{m}$.

Pre-oxidations were directly conducted on the microtensile specimens at $750^{\circ} \mathrm{C}$ for different durations: $5,20,100$ and $200 \mathrm{~h}$. Prior to oxidation, specimens were cleaned in acetone then in ethanol in an ultrasonic bath during 15 minutes each. During the pre-oxidations, the microtensile specimens were hung at the two head radii with platinum wires and the temperature was verified with a K-type thermocouple. It is worth noting that oxide spallation occurred when air cooling after oxidation and remaining oxides were gently mechanically removed using tweezers owing to the low interfacial toughness of the $\mathrm{TiO}_{2}$ oxide. The oxide removal aimed to evaluate the evolution of the tensile properties due to the ONADZ but without the contribution of the oxide layer.

Tensile experiments were conducted at room temperature with a MTS Criterion model 43 electromechanical test system equipped with a $5 \mathrm{kN}$ load-cell and self-tightening grips. The gripping system was purposely adapted in the present study because of the small thickness of the tested microtensile specimens and the oxygen/nitrogen embrittlement (Fig. 1(b)). This solution consisted in adding intermediate soft components, i.e. aluminum spacers, drilled with two holes concentric with the two head radii (Fig. 1(c)). This enabled both functions of the soft spacers instead of knurled and hard conventional grips breaking such specimen when tightening: (1) the friction of the specimen head using the compression of the flat surface, and (2) pin loading at the head radii. Tensile tests were paired with digital image correlation (DIC) techniques to assess both macroscopic deformation of the specimen via non-contact extensometry and full-field strain measurements using PYXEL Python library developed by Passieux et al. [19].

Fractographic analyses were performed using a field emission gun - scanning electron microscope (FEG-SEM) NanoNOVA SEM from Thermo Fisher Scientific in a secondary electron (SE) mode.

\section{Results}

The tensile behavior of the series of $280 \mu \mathrm{m}$-thick microtensile specimens was investigated at room temperature for all the pre-oxidation treatment variants. The macroscopic stressstrain curves of the pre-oxidized specimens are depicted in Fig. 2(a) and compared to the tensile behavior of the non-oxidized specimens. First, it is worth reminding that the oxide layer of the pre-oxidized specimens was removed prior to tensile testing and the cross-section took into account the metal recession due to oxidation. Therefore, the obtained tensile responses of the pre-oxidized specimens typically demonstrated the influence of the ONADZ on the mechanical performance of Ti-alloys without the contribution of the oxide layer. As far as the mechanical properties of the non-oxidized specimens, i.e. the reference specimens, are concerned, differences in tensile behavior were found when duplicating tensile tests. Such differences were attributed to the non-statistically representative specimen in regards to the microstructure dimensions (millimetric grains while $4 \times 2.5 \times 0.3 \mathrm{~mm}^{3}$ sampled volume). However, the strain to failure (STF) is large enough and the tensile strengths (yield strength (YS) and ultimate tensile strength (UTS)) are close enough to be compared with the ones of the pre-oxidized specimens. High temperature exposures in air were found to significantly decrease all the macroscopic tensile performances (YS, UTS, and STF) and this mechanical loss increased with the exposure duration. Five hours at $750^{\circ} \mathrm{C}$ led to a tensile strength drop of approx. $20 \%$ while the ductility is four to six time lower than the non-oxidized specimens. Since the extension of the ONADZ is assumed to follow a parabolic law, all the macroscopic properties were reported in Fig. 2(b) as a function of the square root of the exposure duration at high temperature. YS and UTS were found to roughly follow a linear trend as a function of the square root of the pre-oxidation time. It is worth noting that the scatter between duplicated tests increased with the exposure duration. The STF was found to significantly drop-off even for such short exposure durations and then progressively decreased. The STF yet account for the elastic response, but the plastic deformation was found to more severely decrease, leading to a fully brittle fracture for durations higher than 100 hours for this specimen thickness. The elastic modulus was found to linearly decrease from $110 \pm 5 \mathrm{GPa}$ down to $95 \pm 5 \mathrm{GPa}$ for 20 hours exposures. When the specimen thickness is mainly affected by the oxidation (after $100 \mathrm{~h})$, the elastic properties significantly increased.
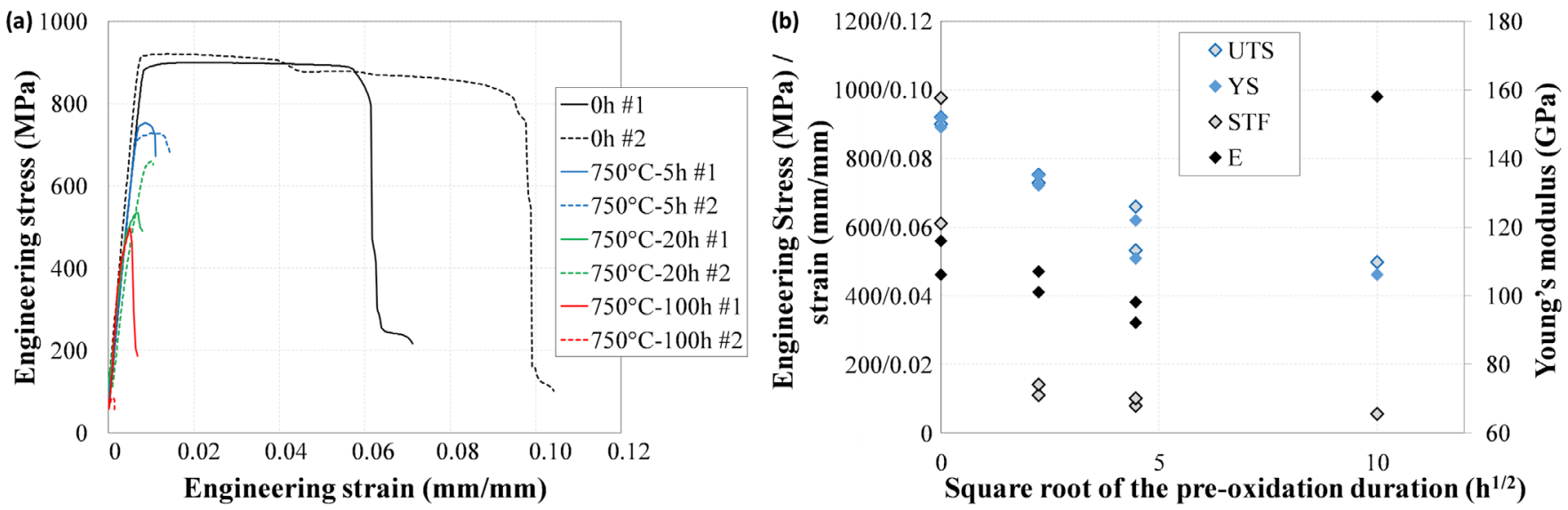

Fig. 2: Tensile properties of the $280 \mu \mathrm{m}$-thick microtensile specimens before and after oxidation: (a) Stress-strain curves for all the pre-oxidation variants), (b) evolution of the macroscopic tensile properties as a function of the square root of the pre-oxidation time

Owing to the strong impact of the $\mathrm{O} / \mathrm{N}$ insertion on the macroscopic tensile properties of the Ti-6Al-4V alloy, the local mechanical response of pre-oxidized specimens was scrutinized for non-oxidized (black representation), $5 \mathrm{~h}$ oxidation (blue representation) and $100 \mathrm{~h}$ pre-oxidation (red representation) at $750^{\circ} \mathrm{C}$ (Fig. 3 ). While the macroscopic stress-strain curves of the non-oxidized and $5 \mathrm{~h}$ oxidized specimens are relatively smooth, the one of the $100 \mathrm{~h}$ oxidized specimen is jerky, leading in a step-by-step slope decrease when deforming. DIC techniques aimed at identifying intense roughly horizontal strain localization (black arrows on $\varepsilon_{y y}$ field red\#2), corresponding to a strain jump in the macroscopic strain-stress response (from stress-strain curves red\#1 to red\#2 in Fig. 3). This horizontal strain localization depicts transverse cracking of the ONADZ (mode I). When further loading, this crack continues to open and other cracks develop as well. Such intense strain localization due to early ONADZ cracking brings explanation in the non-homogeneous deformation of such pre-oxidized specimens and thus their low ductility. After $5 \mathrm{~h}$ pre-oxidation, horizontal cracks also occur at higher stress level but not fully transverse (black arrows on $\varepsilon_{y y}$ field blue\#2). For nonoxidized specimen is concerned, intense strain localization is noticed inclined, and not fully transverse (black arrows on $\varepsilon_{y y}$ field gray\#2). Such strain localizations are representative of slip-band dominated deformation mechanisms and confined in individual grains due to the acicular Widmanstätten microstructure. The diffuse character of the strain localization within an individual grain is due to the accumulation of active slip bands close to each other but also technical means (speckle, spatial resolution, numerical resolution). Despite strain localization due to slip activity, the deformation is much more homogeneous compared to pre-oxidized specimens, leading higher macroscopic ductility. 

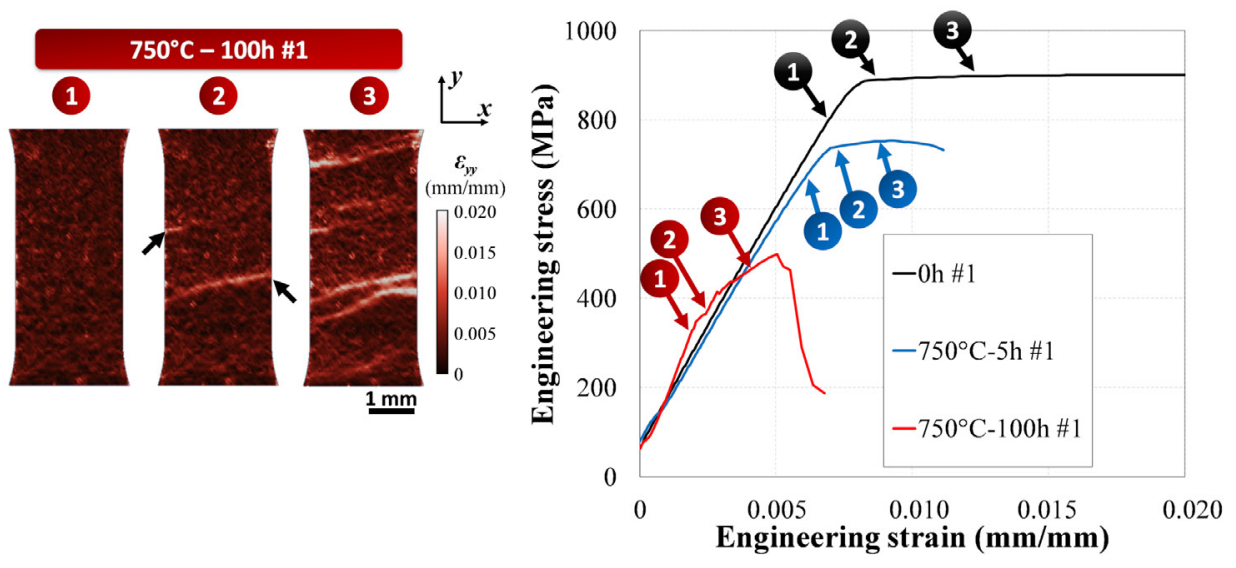
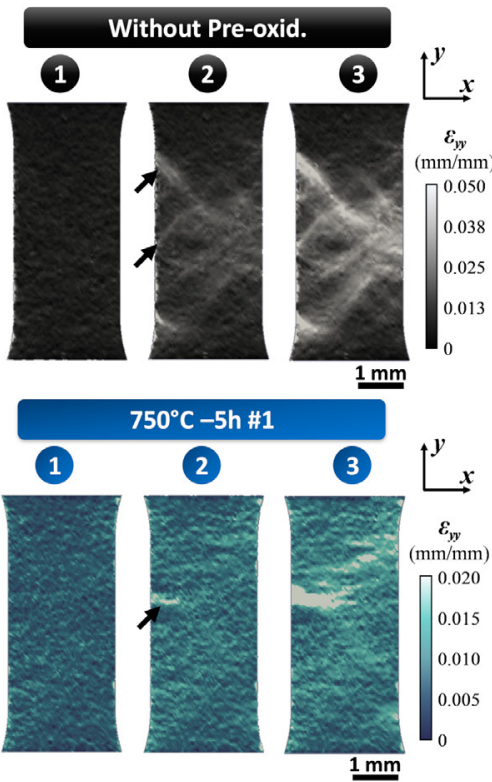

Fig. 3: Macroscopic stress-strain behavior versus local strain field for two pre-oxidized specimens compared to a non-oxidized specimen

Fracture surfaces were observed for all the broken specimens. The fracture surface of the non-oxidized specimen presents dimples and interlamellar fracture features on the whole fracture surface (Fig. 4(a\&d)). The highly distorted fracture surface also reminds the coarse grain microstructure and the deformation of grains independent from others. For pre-oxidized specimens, the fracture surface is divided in a ductile region in the core of the specimens surrounded by a brittle region corresponding to the extension of the ONADZ (Fig. 4(b\&e)). The extension of the ONADZ increases with the exposure time in a parabolic way; the ONADZ after 20h oxidation being roughly two times thicker than the ONADZ after $5 \mathrm{~h}$ oxidation. Interestingly, an insignificant core region remains ductile after $100 \mathrm{~h}$ oxidation while the fracture surface of the $200 \mathrm{~h}$ pre-oxidized specimen is fully brittle (Fig. 4 (c\&f)). Fracture surface of pre-oxidized specimens is flatter than the one of the non-oxidized specimens. When comparing all the specimens with the different thicknesses and pre-oxidation durations, fully brittle fracture surfaces are noticed for the following ratio " $200 \mathrm{~h} / 280 \mu \mathrm{m}$ ", " $100 \mathrm{~h} / 180 \mu \mathrm{m}$ " and " $20 \mathrm{~h} / 100 \mu \mathrm{m}$ ". While such ratios are highly decreasing with the decrease of the specimen thickness, using the following parabolic temporal ratio was found to better suit due to the diffusion process involved in the extension of the ONADZ. At $750^{\circ} \mathrm{C}$, a thin plate made of a coarse grain $\beta$-annealed Ti-6Al-4V alloy would be fully affected by the oxidation when meeting the criteria:

Ti-6Al-4V, 750h in air: $\frac{\sqrt{\text { Pre-oxid.duration }}}{\text { thickness }}>0.50 \pm 0.05 h^{1 / 2} \cdot \mu m^{-1}=\frac{1}{2.0 \pm 0.2} h^{1 / 2} \cdot \mu m^{-1}$
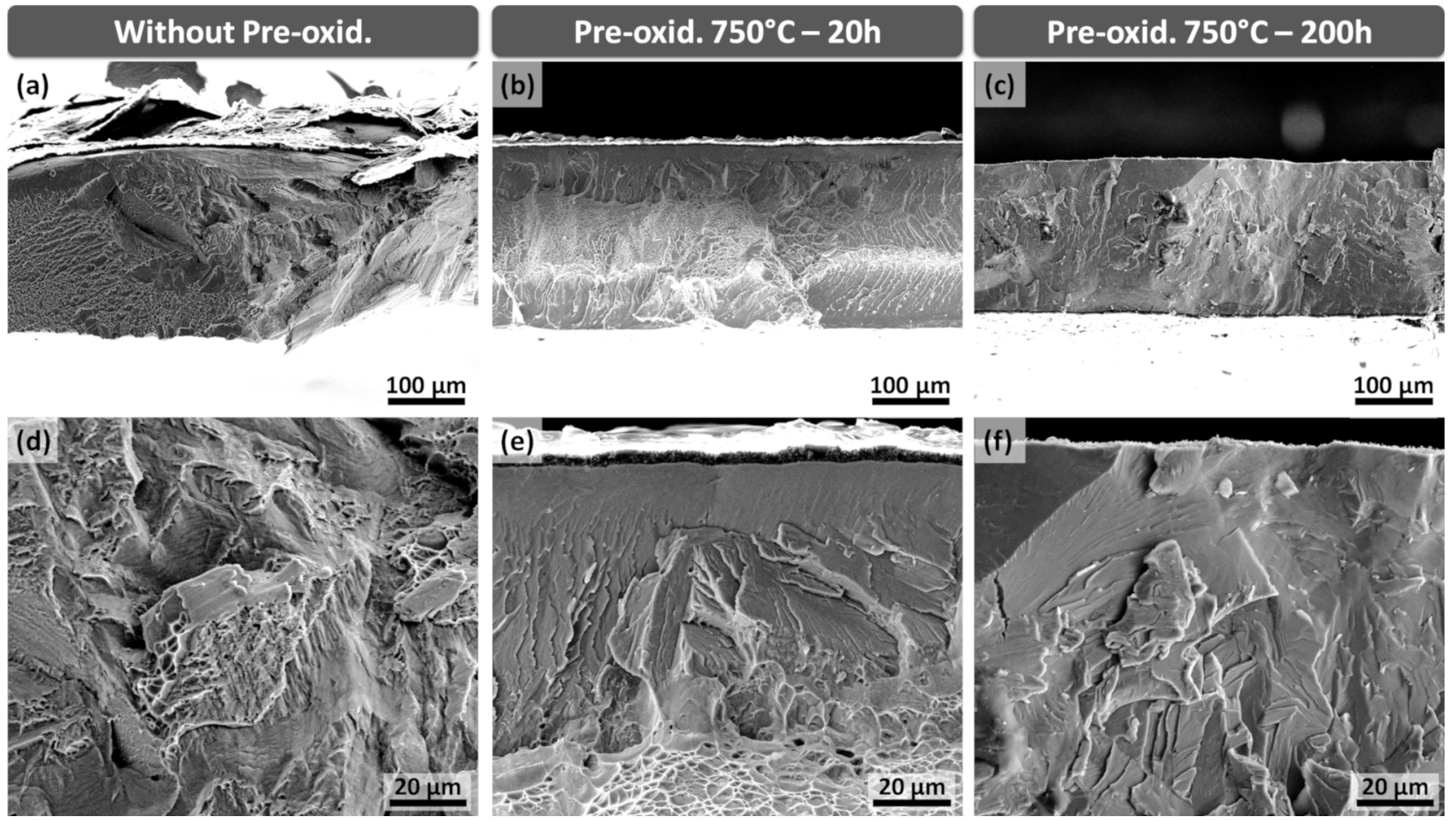

Fig. 4: Fracture surfaces of different pre-oxidized specimens: (a \& d) Non-oxidized specimen, (b \& e) pre-oxidation at $750^{\circ} \mathrm{C}-20 \mathrm{~h}$, (c \& f) pre-oxidation at $750^{\circ} \mathrm{C}-200 \mathrm{~h}$

4. Discussion

The present results straightforwardly link the evolution of the macroscopic tensile properties of a $\beta$-annealed Ti-6Al-4V alloy with the extension of the ONADZ due to pre-oxidation. A decrease of all the macroscopic tensile properties (YS, UTS and STF) was found with the pre-oxidation time. While the ductility loss is consistent with all the reported literature on oxygen embrittlement in Ti alloys $[6,15]$, loss in tensile strengths (YS and UTS) differs from results found on studies working on Ti-alloys with various and homogeneous contents of oxygen (up to 3000ppm) [5-9]. A point to mention is that the increase in YS and UTS was generally reported for high purity alloys with relatively low mechanical strength and for which solid solution strengthening would be important, regardless of minor element additions within the metal. When dealing with industrial alloys such as Ti-6Al-4V, secondary elements such as $\mathrm{Al}, \mathrm{V}, \mathrm{Fe}$, etc. participate in the strengthening of the material by solid solution and precipitation. 
Working with graded materials originated from oxidation and oxygen insertion is not trivial since the stress state within the ONADZ and the non-affected region are unknown. The origin of such stress-states could arise from the expansions of the lattice parameters as a function of the oxygen content, leading to a ONADZ in a compression state and a core in tension, if the remaining Ti-6Al-4V is strong enough not to relax the deformation [6,12]. In addition, the effect of oxygen on the thermal expansion of the ONADZ would also lead to additional strains after oxidation and cooling down to room temperature. Determination of the coefficient of thermal expansion of Ti-alloy as a function of the oxygen content would be beneficial for such stress-state prediction. While the increase in CRSS for all the system variants would normally increase the macroscopic yield strength of the materials $[5,6]$, the gradient of elastic properties $[8,11]$ induced by the oxygen profile could lead to strain concentration and thus early failure owing to the brittle behavior of the ONADZ. Premature cracking due to strain incompatibilities during loading could be a reason of the loss in mechanical strength but needs further documentations. Increasing the oxidation exposure time and/or extracting and testing microtensile specimens within the ONADZ with the technique developed in ref. [20] for accurate positioning extraction would be valuable to answer such dilemma.

\section{Conclusions}

The influence of oxygen and nitrogen insertion due to high temperature oxidation was investigated on the tensile behavior of an annealed Ti-6Al-4V alloy. The main results of the present investigation can be summarized as follows:

1. The extension of the ONADZ defined as the brittle layer, follows a parabolic low with a progression rate of $2.0 \pm 0.2 \mu \mathrm{m} \cdot \mathrm{h}^{-1 / 2}$ at $750^{\circ} \mathrm{C}$;

2. The ONADZ decreases the tensile strength (YS and UTS) but also the ductility (STF) of the pre-oxidized specimens;

3. The ONADZ modifies deformation and fracture mechanisms from confined slip localizations within a grain to fully transverse ONADZ cracking perpendicular to the loading direction.

\section{Acknowledgements}

The authors are particularly grateful to R. Mainguy (CIRIMAT) for specimen machining and J.-C. Passieux (ICA) for new developments in PYXEL. This work was supported by the Agence Nationale de la Recherche (ANR) [ANR-18-CE08-0003; ANR-JCJC-COMPAACT / ANR-13-RMNP-0014; ANR- DUSTI].

\section{References}

[1] M. Peters, J. Kumpfert, C.H. Ward, C. Leyens, Adv. Eng. Mater. 5 (2003) 419-427

[2] J.L. Murray, H.A. Wriedt, J. Phase Equilibria 8 (1987) 148-165

[3] P. Kofstad, P.B. Anderson, O.J. Krudtaa, J. Less-Common Met. 3 (1961) 89-97

[4] C. Dupressoire, A. Rouaix-Vande Put, P. Emile, C. Archambeau-Mirguet, R. Peraldi, D. Monceau, Oxid. Met. 87 (2017) $343-353$

[5] B. Barkia, V. Doquet, J.P. Couzinié, I. Guillot, E. Héripré, Mater. Sci. Eng. A 636 (2015) 91-102

[6] G. Baur, P. Lehr, J. Less-Common Met. 69 (1980) 203-218

[7] J.-P. Couzinie, B. Barkia, V. Doquet, I. Guillot, in: 2012 Int. Hydrog. Conf., Jakson Lake (USA), 2014, pp. 411-419

[8] F.B. Vicente, D.R.N. Correa, T.A.G. Donato, V.E. Arana-Chavez, M.A.R. Buzalaf, C.R. Grandini, Materials. 7 (2014) $542-553$

[9] M.C. Brandes, M. Baughman, M.J. Mills, J.C. Williams, Mater. Sci. Eng. A 551 (2012) 13-18

[10] J.Q. Ren, Q. Wang, X.F. Lu, W.F. Liu, P.L. Zhang, X.B. Zhang, Mater. Sci. Eng. A 731 (2018) 530-538

[11] J. Baillieux, C. Archambeau, P. Emile, D. Poquillon, in: CFM2015, Lyon (France), 2015, pp. 22-25

[12] J. Baillieux, D. Poquillon, B. Malard, J. Appl. Crystallogr. 49 (2016) 175-181

[13] H. Hornberger, C. Randow, C. Fleck, Mater. Sci. Eng. A 630 (2015) 51-57

[14] W.L. Finlay, J.A. Snyder, JOM 2 (1950) 277-286

[15] M. Yan, W. Xu, M.S. Dargusch, H.P. Tang, M. Brandt, M. Qian, Powder Metall. 57 (2014) 251-257

[16] C.E. Shamblen, T.K. Redden, in: Sci. Technol. Appl. Titan., London (UK), 1970, pp. 199-208

[17] T.A. Parthasarathy, W.J. Porter, S. Boone, R. John, P. Martin, Scr. Mater. 65 (2011) 420-423

[18] D. Texier, D. Monceau, J.-C. Salabura, R. Mainguy, E. Andrieu, Mater. High Temp. 33 (2016) 325-337

[19] J. Passieux, R. Bouclier, J. Périé, Exp. Mech. 58 (2018) 1195-1206

[20] D. Texier, D. Monceau, Z. Hervier, E. Andrieu, Surf. Coatings Technol. 307 (2016) 81-90. 